UCRL-JC-133428

Preprint

\title{
Preliminary Demonstration of Power Beaming With Non-Coherent Laser Diode Arrays
}

\author{
Jordin T. Kare \\ Fred Mitlitsky \\ Andrew Weisberg
}

This paper was prepared for submittal to Space Technology and applications International Forum (STAIF-99) Albuquerque, NM Jan. 31-Feb. 4, 1999

February 26, 1999

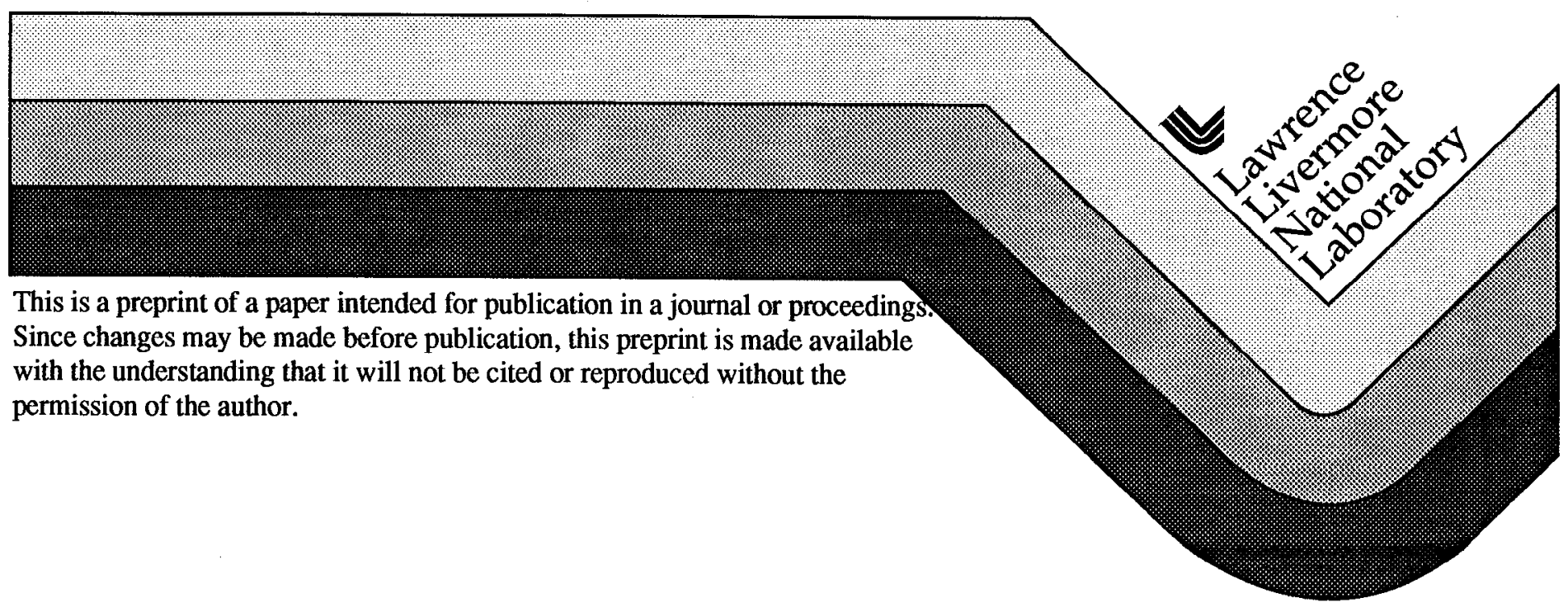




\section{DISCLAIMER}

This document was prepared as an account of work sponsored by an agency of the United States Govemment. Neither the United States Govemment nor the University of Califomia nor any of their employees, makes any warranty, express or implied, or assumes any legal liability or responsibility for the accuracy, completeness, or usefulness of any information, apparatus, product, or process disclosed, or represents that its use would not infringe privately owned rights. Reference herein to any specific commercial product, process, or service by trade name, trademark, manufacturer, or otherwise, does not necessarily constitute or imply its endorsement, recommendation, or favoring by the United States Government or the University of California. The views and opinions of authors expressed herein do not necessarily state or reflect those of the United States Government or the University of California, and shall not be used for advertising or product cndorscment purposes. 


\title{
Preliminary Demonstration of Power Beaming With Non- Coherent Laser Diode Arrays
}

\author{
Jordin T. Kare ${ }^{1}$, Fred Mitlitsky ${ }^{2}$, and Andrew Weisberg ${ }^{2}$ \\ ${ }^{1}$ Kare Technical Consulting, 222 Canyon Lakes Pl., San Ramon, CA 94583 jtkare@ibm.net \\ ${ }^{2}$ Lawrence Livermore National Laboratory, L-174, P.O. Box 808, Livermore, CA 94551 fm@llnl.gov
}

\begin{abstract}
A preliminary demonstration of free-space electric power transmission has been conducted using non-coherent laser diode arrays as the transmitter and standard silicon photovoltaic cell arrays as the receiver. The transmitter assembly used a high-power-density array of infrared laser diode bars, water cooled via integrated microchannel heat sinks and focused by cylindrical microlenses. The diode array composite beam was refocused by a parabolic mirror over a 10 meter path, and received on a $\sim 15 \times 25 \mathrm{~cm}$ panel of thinned single crystal high efficiency silicon solar cells. The maximum cell output obtained was several watts, and the cell output was used to drive a small motor. Due to operating constraints and unexpected effects, particularly the high nonuniformity of the output beam, both the distance and total received power in this demonstration were modest. However, the existing transmitter is capable of supplying several hundred watts of light output, with a projected received electric power in excess of 200 watts. 'The source radiance is approximately $5 \times 10^{9}$ $\mathrm{W} / \mathrm{m}^{2}$-steradian. With the existing $20 \mathrm{~cm}$ aperture, useful power transmission over ranges to $\sim 100$ meters should be achievable with a DC to DC efficiency of greater than $10 \%$. Non-coherent sources of this type are readily scalable to powers of tens of kilowatts, and with larger apertures can be used directly for power transmission up to several kilometers. Future non-coherent diode laser sources may be suitable for power transmission over hundreds of kilometers. Also, the experience gained with non-coherent arrays will be directly applicable to power beaming systems using coherent diode arrays or other array-type laser sources.
\end{abstract}

\section{INTRODUCTION}

Wireless power transmission by laser has been proposed repeatedly, e.g., (Landis, 1994). The primary advantage of coherent laser power transmission over microwave transmission is that the laser wavelength is much shorter, so longer ranges can be achieved with smaller transmit and receive apertures. Unfortunately, the high cost, low electrical efficiency, and limited selection of wavelengths of coherent laser sources has prevented their use in any practical application, or even realistic demonstration, of power transmission.

However, laser power transmission also has other advantages over microwaves:

- Photovoltaic receivers may already exist on the desired platform, or may be easier to incorporate than rectennas

- Optical power can be transmitted where RF cannot: in RF-sensitive environments, through small apertures (including optical fibers), through RF shields, etc.

- Optical power can be concentrated to very high power density at a receiver

If the requirement for coherence is relaxed, high-power laser diode arrays can provide arbitrary optical power at efficiencies of 40 to $50 \%$, and wavelengths nearly ideally matched to both $\mathrm{Si}$ and GaAs photovoltaic cells, at comparatively low cost.

With the development of densely-packed laser diode arrays and microlens focusing (1- or 2-dimensional lenses mounted directly in front of individual laser diodes) the radiance (power per unit area per unit solid angle) available from noncoherent diode arrays has reached $\sim 10^{11} \mathrm{~W} / \mathrm{m}^{2}$-sr, three to four orders of magnitude higher than non-laser sources such as high pressure arc lamps. This is sufficient for selected power beaming applications, including laserpowered experimental aircraft and power transmission between co-orbiting spacecraft. Foreseeable technical 
improvements ${ }^{1}$ can provide noncoherent radiances in excess of $10^{13} \mathrm{~W} / \mathrm{m}^{2}$-sr, which is sufficient for power transmission to or from low Earth orbit.

To gain an understanding of the possibilities and difficulties of non-coherent laser power transmission, the authors attempted to assemble a small, short-range power beaming system using available hardware. To our knowledge, this is the first demonstration of free-space power transmission using an noncoherent laser diode source.

\section{LASER SOURCE}

The laser source used was a microchannel-cooled diode array originally developed for diode pumping of solid state laser media. These arrays are described in detail in (Beach, 1990). The array used consisted of 25 individual "wafers"; each $0.1 \times 1 \times 1.5 \mathrm{~cm}$ wafer having a laser diode bar along one edge and a set of water cooling channels. The wafers are stacked between metal end blocks which provide both electrical contacts and water inlet and outlet connections.

The diode bars, fabricated by LLNL, produce approximately 25 watts CW, with an output divergence of, nominally, $0.1 \times 1$ radians (Figure 2a). The cylindrical microlens converges this beam on the "wide" axis to produce an output beam with divergence nominally $0.1 \times 0.01$ radians (Figure $2 b$ ).

The assembly used for this experiment was built to pump a high average power solid state laser (Comaskey, 1992) and had previously been measured to operate at up to 578 watts at an operating point of $60 \mathrm{~A}$ and $43.1 \mathrm{~V}$, for an efficiency (DC to optical power) of $22.4 \%$ (Mitchell, 1997). Similar arrays operate at efficiencies as high as 45 $50 \%$. In this experiment, the source was operated from a regulated DC power supply at a maximum voltage of 44 volts and a maximum current of $35 \mathrm{~A}$. At these conditions the array optical power output was measured at $243 \mathrm{~W}$, as described below, for an efficiency of $16 \%$. Power transmission tests were run at $42 \mathrm{volts} / 20 \mathrm{~A}$; at these conditions the laser power output was measured at $28.6 \mathrm{~W}$. The associated efficiency is $3.4 \%$. This low efficiency is characteristic of laser diode arrays operated only slightly above their threshold current. The output wavelength was near $850 \mathrm{~nm}$ in the near infrared.

\section{OPTICS}

A $20 \mathrm{~cm}$ diameter parabolic mirror with a focal length of $1.2 \mathrm{~m}(\mathrm{f} / 6)$ was used to reimage the source onto the receiving array. Since in the "wide" direction of the array, its output was approximately f/10, the beam nearly filled

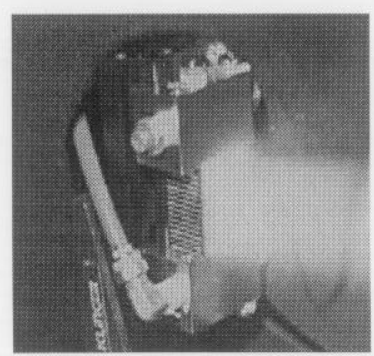

FIGURE 1. Laser

Assembly

the mirror in one direction with the array located near the focal point. The beam illuminating the mirror was significantly narrower in the other dimension; a future experiment could use an anamorphic optic to diverge the beam in the "narrow" direction to fill (and thus efficiently use) the mirror.

\footnotetext{
${ }^{1}$ An array of single mode diffraction-limited sources has on-axis radiance $\mathrm{P} / \lambda^{2}$, where $\mathrm{P}$ is the power of a single source. At $0.8 \mu \mathrm{m}$ wavelength, the array radiance reaches $10^{13} \mathrm{~W} / \mathrm{m}^{2}$-sr when individual sources -- single mode diodes or, e.g., phase-locked subarrays -- produce greater than 6.4 watts. Combining sources with different polarizations or wavelengths can also increase radiance.
} 


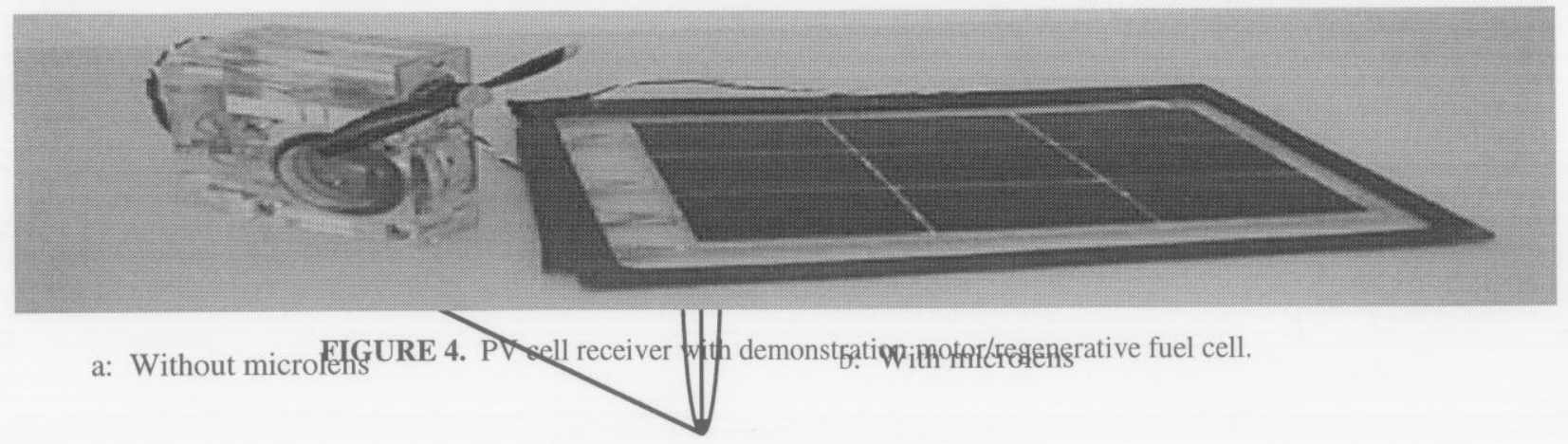

FIGURE 2. Diode array beam divergence.

A $30 \mathrm{~cm}$ square plane first surface mirror with a gold overcoat for high infrared reflectivity was used to bounce the beam to provide a longer beam path within the available laboratory space. The overall optical arrangement is sketched in Figure 3.

The beam profile at various points was measured using a diffuse target (white paper) and a Cohu 4915 CCD-camera. The CCD camera provides relative intensity information across the beam, which was analyzed using a BVAM101 BeamView Analyzer from Big Sky Corp.. A Coherent Labmaster power meter placed directly in the array output beam was used to measure the absolute power into a $1.8 \mathrm{~cm}$ diameter circular aperture, and thus calibrate the profile sensor.

\section{RECEIVER}

The receiver consisted of an array of 9 high efficiency thin film Si photovoltaic cells manufactured by Sunpower, Inc., with an active area of $3.8 \times 7.9 \mathrm{~cm}$. These cells were grouped in two series strings, one of 6 cells and one of 3 cells, as shown in Figure 4. These cells had an efficiency in sunlight of $18 \%$. They were part of a lot originally intended for use in a solar-powered airplane project, which was also the source of the demonstration regenerative fuel cell used as a test load (Mitlitsky 1993). These particular cells were laminated between plastic sheets of "viewgraph protector" material (polystyrene) as part of a demonstration package, a fact which proved detrimental to the experiment. The cells were interconnected with soldered copper ribbon.

\section{RESULTS}

The transmitted beam was substantially less uniform than had been hoped. A sample beam profile at the receiver

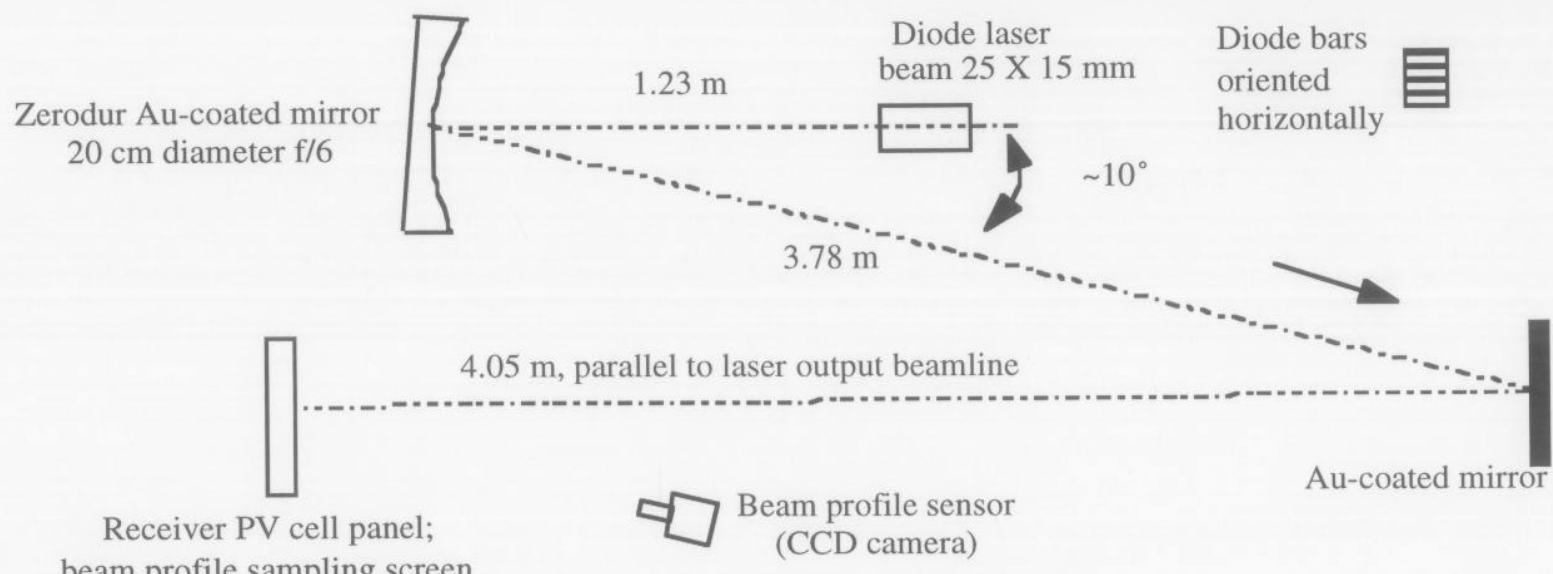

FIGURE 3. Optical layout, viewed from above. 
location is shown in Figure 5. It was anticipated that directly reimaging the diode array on the receiver would give a nonuniform flux at the receiver, since the array surface is not uniformly bright, but that a comparatively small defocusing would blur the stripe pattern and yield a uniform spot. The degree of defocusing available with this small source and short range was not large, however. Also, the uniformity of the diode bars was poor, especially at the near-threshold operating conditions, creating large-scale variations in output across the transmitter surface.

However, the high peak power observed in one section of the output pattern was entirely unexpected. We believe this was due to misalignment of the microlens on one diode bar, with the result that its output was directed about 2 beamwidths away from the nominal beam direction. With the particular ranges and optics used, this would cause both a dip in flux at the receiver where that bar should have illuminated, and a peak where two bar outputs overlapped.

Due to the nonuniformity, operating the transmitter at even $~ 20$ watts resulted in localized hot spots at the receiver. Changes in the surface appearance of the receiver during operation suggested that the plastic cover and/or the lowtemperature solder interconnections were approaching melting. Post-experiment examination of the receiver revealed a crack in one cell. Operation with a larger receiver area (a $\sim \mathrm{m}^{2} \mathrm{PV}$ cell panel) and higher power was planned but not completed.

\section{Power Received}

Despite these problems, the 3-cell string was placed under the peak of the beam pattern with the laser operating at 42 $\mathrm{V}, 20 \mathrm{~A}$. The output of the 3-cell string was measured at:

Voc (open circuit voltage): $1.93 \mathrm{~V}$ (average; fell from 1.99 to 1.85 volts as the receiver was heated by the beam)

Isc (short circuit current): $1.19 \mathrm{~A}$

Assuming a power factor (ratio of Voc * Isc to power into a matched load) of $85 \%$, the power extractable by a matched load would have been $1.8 \mathrm{~W}$. Due to the nonuniform illumination, the estimated power available from the full 9-cell receiver was between 3.6 and 4.5 watts.

The flux at the receiver, at the pattern peak, was measured with the power meter at $1850 \mathrm{~W} / \mathrm{m}^{2}$, or roughly 1.5 times full solar illumination. Integrating the beam profile over the active cell area, vs. the total integrated beam profile, gave the fraction of the laser power illuminating the cells as $22 \%$. At $28.6 \mathrm{~W}$ laser output, and with mirror losses of $\sim 10 \%$, the optical power on the 3-cell string was approximately $5.7 \mathrm{~W}$, giving a cell efficiency of $1.8 / 5.7=32 \%$.

There is some uncertainty about this value, as a similar integration estimates the fraction of the laser power entering the power meter aperture $\left(2.6 \mathrm{~cm}^{2}\right)$ as 0.0081 ; this would correspond to total beam power at the receiver of $(.185 * 2.6 / 0.0081)=59.5$ watts, and thus a laser power of $\sim 65$ watts, significantly higher than the $28.6 \mathrm{~W}$ previously measured at this laser current. The source of the discrepancy is not known. The corresponding PV cell efficiency if this power estimate is correct is $\sim 14 \%$, which would be surprisingly low.
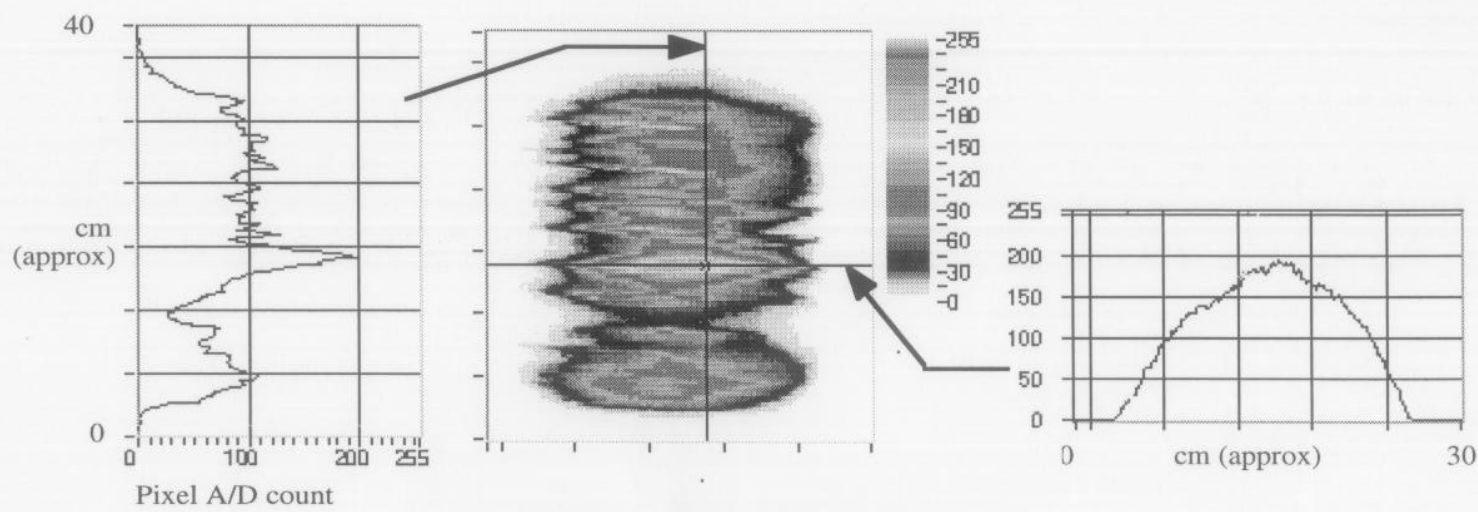

FIGURE 5. Beam profile at receiver. 


\section{Fuel Cell/Motor Operation}

The receiver was used to directly drive a small $(1 \mathrm{~W})$ electric motor with the 3-cell string, and to simultaneously charge a demonstration-sized regenerative fuel cell with the 6-cell string. The fuel cell, operating as an electrolyzer, developed bubbles indicating significant gas production at a laser current between 18 and $20 \mathrm{~A}$.

\section{DISCUSSION}

This effort was unfortunately cut short after the first "power transmission". As a result, the overall efficiency and power transmitted were both low and poorly measured. The cstimated efficiency and power are shown in Table 1.

However, the required steps to improve this efficiency in the existing experimental setup are clear:

1. Operate at substantially higher transmitter power to improve transmitter efficiency and uniformity.

2. Improve the uniformity of the beam at the receiver. At a minimum, the worst-misaligned diode bar may be blocked off to reduce the severest "hot spot". Some types of "beam scramblers", including the lens ducts used to couple diode array outputs to solid-state laser media, are nearly radiance-preserving, and can be used to generate a more uniform output.

With these two improvements, we would anticipate being able to transmit in excess of 100 watts over $\sim 30$ meters, with an end-to-end efficiency of approximately $10 \%$, using a larger $(\sim 1 / 2$ meter square) receiver array

A third upgrade would use an anamorphic lens or prism to fill the available focusing reflector aperture, rather than using only a narrow strip. This would extend the usable range to 60 to 100 meters, which would exceed the available laboratory path and require moving the tests outdoors or to a larger facility.

Since the range is linearly proportional to the transmitting aperture, larger optics could significantly extend the useful range. Using a 1 meter aperture (of substantially less than telescope quality), the existing transmitter could send useful power (nominally defined as received flux * PV efficiency $>$ sunlight flux * PV efficiency in sunlight) over approximately $1 \mathrm{~km}$.

There are few fundamental limits to increasing the transmitter fluence substantially. In particular, higher power diode bars with 1- or 2-dimensional microlens arrays can clearly provide one more order of magnitude in fluence in the foreseeable future. Arrays of single-mode diodes, which can be accurately focused on both axes, can potentially provide $10^{-6}$ steradian divergence from diodes on $<1 \mathrm{~mm}$ centers; at 1 watt per diode, such arrays could exceed $10^{12}$ $\mathrm{W} / \mathrm{m}^{2}$-sr.

The problem of uniformity will be automatically reduced in larger systems, because the number of individual diode bars will be greatly increased. In the current system, defocusing the system sufficiently to significantly smooth the received flux also spread the overall beam substantially; this would be much less true in a system with 100 or more individual diode arrays. Alternatively, large systems may use multiple small transmitting apertures, since the received flux is independent of the distribution of the transmitting aperture area; in this case many individual

TABLE 1. Demonstrated and Projected Efficiencies of Noncoherent Power Beaming

\begin{tabular}{|l|c|c|c|c|c|c|c|c|c|}
\cline { 2 - 11 } \multicolumn{1}{c|}{} & \multicolumn{3}{c|}{ Demonstrated } & \multicolumn{3}{c|}{ Projected $^{\mathrm{a}}$} & \multicolumn{3}{c|}{ Achievable $^{\mathrm{b}}$} \\
\hline & $\begin{array}{c}\text { Power, } \\
\text { W }\end{array}$ & $\begin{array}{l}\text { Effic- } \\
\text { iency, } \\
\%\end{array}$ & $\begin{array}{l}\text { Cumu- } \\
\text { lative } \\
\text { Eff., } \%\end{array}$ & $\begin{array}{l}\text { Power, } \\
\mathrm{W}\end{array}$ & $\begin{array}{l}\text { Effic- } \\
\text { iency, } \\
\%\end{array}$ & $\begin{array}{l}\text { Cumu- } \\
\text { lative } \\
\text { Eff., } \%\end{array}$ & $\begin{array}{l}\text { Power, } \\
\text { W }\end{array}$ & $\begin{array}{l}\text { Effic- } \\
\text { iency, } \\
\%\end{array}$ & $\begin{array}{l}\text { Cumu- } \\
\text { lative } \\
\text { Eff., } \%\end{array}$ \\
\hline DC power & 860 & & 100 & 1540 & & 100 & 2000 (nominal) & 100 \\
\hline Diode array output & 28.6 & 3.4 & 3.4 & 243 & 16 & 16 & 900 & 45 & 45 \\
\hline Transmission & 25.7 & 90 & 3.1 & 219 & 90 & 14.4 & 810 & 90 & 41 \\
\hline $\begin{array}{l}\text { Receive area/beam } \\
\text { area }\end{array}$ & 5.7 & 22 & 0.67 & 109 & 50 & 7.2 & 650 & 80 & 33 \\
\hline Cell efficiency & 1.8 & 32 & 0.21 & 35 & 32 & 2.3 & 260 & 40 & 13 \\
\hline
\end{tabular}

${ }^{\text {a }}$ Using the existing source and PV cells in a follow-on experiment

b Using currently-available laser diodes and PV cells 
nonuniform patterns would be averaged. However, this will remain a key issue for noncoherent array transmissions, and further analysis and experiments on the effect of such nonuniform illumination on PV cell arrays is needed.

\section{ACKNOWLEDGMENTS}

This work was funded by the NASA Marshall Space Flight Center. The authors wish to thank Edward E. Montgomery IV of NASA for his assistance in obtaining support, Scott Mitchell and Blake Myers for their extensive assistance in the conducting these tests, and Camille Bibeau for permission to use the LLNL Laser Program's hardware and facilities for this effort. Work at LLNL is conducted under the auspices of the U.S. Department of Energy, Contract W-7405-Eng-48.

\section{REFERENCES}

Beach, R., Mundinger, D., Benett, W., Sperry, V., Comaskey, V., and Solarz, R., "High-Reliability Silicon Microchannel Submount for High Average Power Laser Diode Arrays", Appl. Phys. Lett. 56, pp. 2065-2067 (1990).

Comaskey, B. J., et. al., " High Average Power Diode Pumped Slab Laser", ILEE J. of Quantum Electronics, Vol. 21, No. 4, April 1992, pp. 992-996, cf. p. 993 and Fig. 2.

Landis, G., "Applications for Space Power by Laser Transmission," in Laser Power Beaming, edited by J. V. Walker and E. E. Montgomery IV, Los Angeles, SPIE Conference Proceedings Vol. 2121, 1994, pp. 252-255.

Mitchell, S., Lawrence Livermore National Laboratory, personal communication, 1997.

Mitlitsky, F., Colella, N. J., Myers, B., and Anderson, C. J., "Regenerative Fuel Cells For Solar Powered Aircraft," 28th Intersociety Energy Conversion Engineering Conference (IECEC), August 9-13 (1993); UCRL-JC-113485. 